\title{
Factors Influencing Breastfeeding in Ireland
}

\author{
L. Mullaney ${ }^{1}$, A. Doolan ${ }^{2}$, A. O'Higgins ${ }^{3}$, M. Sheridan-Pereira ${ }^{2}$, D. McCartney ${ }^{1}$ \\ and M. J. Turner ${ }^{3}$ \\ ${ }^{1}$ School of Biological Sciences, Dublin Institute of Technology, Dublin 8, Republic of Ireland, ${ }^{2}$ Department of \\ Pediatrics, Trinity College, Dublin 2, Republic of Ireland and ${ }^{3}$ UCD Centre for Human Reproduction, CWIUH, \\ Dublin 8, Republic of Ireland
}

The multiple maternal and infant benefits of breastfeeding are widely established ${ }^{(1)}$. Rates of breastfeeding in Ireland are very low by international standards. Only 56\% of mothers currently initiate breastfeeding in Ireland compared to $81 \%$ in the UK and over $91 \%$ in Scandinavian countries ${ }^{(2)}$. Higher maternal BMI has been negatively associated with breastfeeding duration ${ }^{(3,4)}$. Other significant risk factors for early termination of breastfeeding include young maternal age, smoking and family infant feeding practices ${ }^{(5,6)}$. The aim of this study was to investigate breastfeeding initiation rates and factors associated with breastfeeding initiation.

Women were recruited at their convenience in July 2012 after sonographic confirmation of a singleton pregnancy in the first trimester. Maternal body composition was then measured using 8-electrode bioelectrical impedance analysis. Maternal smoking status, ethnicity, parity and breastfeeding data were collected when the baby was 4 months of age.

The mean age of the 251 women recruited was $30 \cdot 1 \pm 5 \cdot 1$ years and the mean BMI was $25 \cdot 3 \pm 5 \cdot 0 \mathrm{~kg} / \mathrm{m}^{2}$ with $14 \cdot 3 \%$ women classified as obese. Forty-two percent were primigravidas. Sixty percent of women reported that they breastfed from this latest pregnancy. Women who were themselves breastfed as infants were more likely to breastfeed than not to breastfed $(36 \%$ vs. $5 \%(n=13)$ respectively, $p<0.001)$. Women with 1 or less children were more likely to breastfeed than not to breastfed $(65 \%$ vs. $35 \%$ respectively, $p<0.05)$. A greater percentage of non-Irish Europeans than Irish women breastfed (93\% of non-Europeans breastfed, whereas $45 \%$ of Irish breastfed $p<0.001)$. Current smokers were less likely to breastfeed then those who never smoked (43\% vs. $60 \%$ respectively, $p=0.008) .63 \%$ of women with a BMI less than $30 \mathrm{~kg} / \mathrm{m}^{2}$ breastfed, whereas $41 \%$ of women with a BMI greater than $30 \mathrm{~kg} / \mathrm{m}^{2}$ breastfed $(p=0 \cdot 02)$. Maternal age was not associated with breastfeeding rates.

In our cohort of women recruited as part of ongoing research into maternal body composition, Irish women are less likely to breastfeed than non-Irish women. Women with more children, women with a higher BMI, and women who smoke are also less likely to breastfeed. In addition, we found that women who were themselves breastfed are more likely to breastfeed their own infants. Interventions that include the family unit in the promotion of breastfeeding may therefore be beneficial.

1. American Academy of Paediatrics (2012). Paediatrics 129, 827-841.

2. Economic and Research Institute (ESRI) (2012). Health Service Executive. Available from: https://www.esri.ie/news_events/latest_press_releases/ breastfeeding_in_ireland_/index.xml [3 Mar 2014].

3. Liu J, Smith MĞ, Dobre MA, Ferguson JE (2010). Obesity (Silver Spring) 18, 175-182.

4. Guelinckx I, Devlieger R, Bogaerts A, Pauwels S, Vansant G (2012). Public Health Nutr 15, 840-848.

5. Kehler HL, Chaput KH and Tough SC (2009). Can J Public Health 100, 376-380.

6. Fitzpatrick CC, Fitzpatrick PE \& Darling MR (1994). Ir Med J 87, 145-146. 